\title{
Asthma Controller Medication Adherence, Risk of Exacerbation, and Use of Rescue Agents Among Texas Medicaid Patients with Persistent Asthma
}

\author{
Tatiana Makhinova, MS; Jamie C. Barner, PhD; Kristin M. Richards, PhD; and Karen L. Rascati, PhD
}

\begin{abstract}
BACKGROUND: Adherence to asthma long-term controller medications is one of the key drivers to improve asthma management among patients with persistent asthma. While suboptimal use of controller medications has been found to be associated with more frequent use of oral corticosteroids (OCS), few studies exist regarding the relationship between adherence to controller therapy and the use of short-acting beta2-agonists (SABAs). A better understanding of the association between adherence to asthma controller agents and use of reliever medications will help health care providers and decision makers enhance asthma management.
\end{abstract}

OBJECTIVE: To determine if there is a relationship between asthma controller adherence, risk of exacerbation requiring $0 \mathrm{CS}$, and use of asthma rescue agents.

METHODS: Texas Medicaid claims data from January 1, 2008, to August 31,2011 , were retrospectively analyzed. Continuously enrolled patients aged 5-63 years with a primary diagnosis of asthma (ICD-9-CM code 493) and with 4 or more prescription claims for any asthma medication in 1 year (persistent asthma) were included. The index date was the date of the first asthma controller prescription, and patients were followed for 1 year. The primary outcome variables were SABA (dichotomous: $<6$ vs. $\geq 6$ ) and OCS (continuous) use. The primary independent variable was adherence (proportion of days covered [PDC]) to asthma long-term controller medications. Covariates included demographics and nonstudy medication utilization. Multivariate logistic and linear regression analyses were employed to address the study objective.

RESULTS: The study sample $(n=32,172)$ was aged $15.0 \pm 14.5$ years, and adherence to controller therapy was $32.2 \% \pm 19.7 \%$. The mean number of SABA claims was $3.7 \pm 3.1$, with most patients having $1-5$ claims $(73.2 \%)$, whereas $19.4 \%$ had $\geq 6$ SABA claims. The mean number of OCS claims was $1.0 \pm 1.4$. Adherent $(P D C \geq 50 \%)$ patients were $96.7 \%(0 \mathrm{R}=1.967 ; 95 \%$ $\mathrm{Cl}=1.826-2.120)$ more likely to have $\geq 6$ SABA claims when compared with nonadherent $(\mathrm{PDC}<50 \%)$ patients $(P<0.001)$. As for $0 \mathrm{CS}$ use, adherent patients had 0.11 fewer claims compared with nonadherent patients $(P<0.001)$. Importantly, patients with $\geq 6$ SABA claims had 0.7 more $0 \mathrm{CS}$ claims compared with patients with $<6$ claims for SABA $(P<0.001)$. The odds of having $\geq 6$ SABA claims were higher for concurrent dual therapy users, older age, males, African Americans and higher number of nonstudy medications $(P<0.001)$. Dual therapy users, younger age, Hispanic ethnicity, and higher number of nonstudy medications were associated with an increase in 0CS use $(P<0.005)$.

CONCLUSIONS: Adherence to long-term controller medications was suboptimal among patients with asthma. Adherent patients had fewer OCS claims, indicating that adherence to controller therapy is critical in preventing asthma exacerbations requiring OCS use. Although there was a positive relationship between adherence to long-term controller medication and
SABA use, increased SABA use served as a predictor of increased OCS use, which indicates poor asthma control. Health care providers should be aware of OCS and SABA use among patients who are both adherent and nonadherent to asthma controller medications.

J Manag Care Spec Pharm. 2015;21(12):1124-32

Copyright $\odot 2015$, Academy of Managed Care Pharmacy. All rights reserved.

\section{What is already known about this subject}

Regular use of asthma long-term controller medications is one of the key drivers to improve persistent asthma management, yet medication adherence among patients with asthma is suboptimal, often ranging from $30 \%-40 \%$ in practice.

Poor adherence is associated with higher risk for exacerbations requiring oral corticosteroid (OCS) use; however, conflicting results exist regarding the association between adherence to controller therapy and frequency of short-acting beta2-agonists (SABA) use.

Little is known whether excessive use of SABA may be associated with exacerbations requiring OCS use.

\section{What this study adds}

Real-world information is presented regarding the relationship between adherence to asthma controller medications and the use of asthma rescue agents and how the findings can be applied to asthma management practice.

Increased SABA use served as a predictor of increased OCS use, which indicates poor asthma control.

This study demonstrated that even patients who were adherent to controller therapy had evidence of excessive SABA use. Patients should be thoroughly evaluated by health care providers for signs of ineffective asthma management (e.g., improper inhaler technique and suboptimal use of long-term controller therapy), which is associated with higher risk of asthma exacerbation.

A sthma is reported as a "common, deadly, disruptive, and expensive" condition, so the question of what can be done to improve its management is of interest. ${ }^{1}$ Several factors contribute to poor asthma management, one of which is low adherence to long-term controller medications (i.e., inhaled corticosteroids [ICS], long-acting beta-agonists 
[LABA], and leukotriene receptor agonists [LTRA]) among patients with persistent asthma. ${ }^{2}$ Nonadherence contributes to poor asthma control in conjunction with increased mortality; increased health care utilization (hospitalizations and emergency department [ED] visits); reduced lung function; and decreased quality of life..$^{3-9}$ Medication adherence to controller therapy is consistently low, ranging between 30\% and 70\% overall and from $30 \%$ to $40 \%$ in clinical practice settings. ${ }^{10-16}$ Therefore, addressing adherence to controller medications is critical in asthma management.

Several studies have demonstrated that low adherence to controller medications is associated with an increase in the number of hospitalizations and ED visits. ${ }^{3,8-10,17-21}$ Other indicators of poor asthma control are use of oral corticosteroids (OCS) and excessive use of short-acting beta2-agonists (SABA; usually 6 and more claims per year). ${ }^{22-26}$ Asthma symptoms that require OCS or frequent SABA use (more than 2 days per week) signal ineffective asthma management and may serve as a preliminary indicator of poor asthma control. ${ }^{2}$ Recent Global Initiative for Asthma guidelines stressed the importance of assessing patients with excessive SABA use and ICS nonadherence, which are among risk factors for poor outcomes. ${ }^{27}$

Studies have found inconsistent results regarding the relationship between controller therapy adherence and OCS/SABA use. Several studies have reported that patients with higher controller therapy adherence were less likely to use OCS and SABA inhalers. ${ }^{3,10,18,28,29}$ However, other studies have found no association between adherence to controller therapy and OCS/ SABA use, and 1 study found a positive association between the level of adherence and SABA use..$^{10,17,30,31}$

Williams et al. (2004) found that a $25 \%$ increase in ICS nonadherence was significantly associated with an increase in the number of OCS fills (relative risk $[\mathrm{RR}]=1.49,95 \%$ confidence interval $[\mathrm{CI}]=1.10-2.02, \mathrm{P}<0.05)$ in a prospective cohort study. ${ }^{3}$ Similarly, Delea et al. (2008) found in a large retrospective database study that every $25 \%$ of improvement in ICS adherence was associated with a reduction in OCS use by $3 \%$ (odds ratio $[\mathrm{OR}]=0.97,95 \% \mathrm{CI}=0.94-0.996, P=0.027$ ) ${ }^{18}$ Regarding SABA use, patients with low ICS adherence (medication possession ratio $[\mathrm{MPR}]<25 \%$ ) filled more SABA inhalers compared with patients with high ICS adherence (MPR $\geq 75 \%$; $\mathrm{OR}=0.83,95 \% \mathrm{CI}=0.77-0.89, \mathrm{P}<0.001$ ). Every $25 \%$ increase in ICS adherence was associated with a reduction in SABA use by $10 \%(\mathrm{OR}=0.90,95 \% \mathrm{CI}=0.89-0.92, \mathrm{P}<0.001) .{ }^{18}$ Although the relationship between controller therapy adherence and SABA use was negative, a study conducted by Smith et al. (2009) showed that patients who were highly adherent (measured by $>80 \%$ of subjects who filled their prescriptions within 60 days of the prior refill) to controller medications filled more SABA inhalers compared with those with lower adherence (measured by $<50 \%$ of subjects who filled their prescriptions within 60 days of the prior refill; incident rate ratio $=1.62$,
95\% $\mathrm{CI}=1.26-1.97, \mathrm{P}<0.001) .{ }^{31} \mathrm{~A}$ better understanding of this association is needed.

The objective of this study was to evaluate the relationship between asthma controller adherence and SABA and OCS use utilizing a large retrospective database.

\section{Methods}

\section{Data Source and Sample Inclusion Criteria}

Texas Medicaid enrollment, medical services, and prescription claims data from January 1, 2008, to August 31, 2011, were used. The study inclusion criteria were patients aged 5 to 63 years at index who were continuously enrolled for at least 18 months (i.e., 6 months pre-index and 12 months post-index date), diagnosed with asthma (International Classification of Diseases, Ninth Revision, Clinical Modification [ICD-9-CM] code 493.xx), and had 4 or more prescription claims for any asthma medication in 1 year. Patients younger than 5 years were excluded because of possible wheezing symptoms that can be incorrectly labeled as asthma, and patients aged 63 years and older were excluded because of potential dual eligibility with Medicare. Persistent asthma was defined based on the criterion of 4 or more prescription claims for any asthma medication in 1 year, which was established by the National Committee for Quality Assurance (NCQA). ${ }^{32}$ The index date was defined as the first prescription in a series of 4 or more prescription claims for any asthma medication over a l-year period of observation between July 1, 2008, and August 31, 2010. Patients were included if they had at least 2 claims for the same study asthma controller medication (ICS, LTRA, and ICS plus LABA) in the 12-month postindex period and did not have claims for any asthma controller medication within the 6-month pre-index period. Patients with diagnoses of chronic obstructive pulmonary disease (ICD-9-CM codes 496.00, 496.01, 493.20, or 493.21) or cystic fibrosis (ICD9-CM codes 277.00 or 277.01 ) were excluded.

\section{Study Design and Variables}

A retrospective cohort design was used. First, the groups were identified based on the index medication prescribed: monotherapy controller medications (ICS, LTRA) and dual therapy (fixed dose dual therapy, concurrent dual therapy). Asthma controller medications included ICS (beclomethasone, budesonide, ciclesonide, flunisolide, fluticasone, mometasone, and triamcinolone); LTRA (montelukast, zafirlukast, and zileuton); ICS plus LABA (concurrent use: an ICS plus formoterol or salmeterol; fixed dose: fluticasone/salmeterol, budesonide/ formoterol, or mometasone/formoterol); ICS plus LTRA (an ICS plus an LTRA); and ICS/LABA fixed dose plus LTRA. Dual therapy of fixed dose medications did not require additional data manipulation, since a single canister contains 2 medications. However, for concurrently used dual therapy, the following strategies were employed: (a) the 2 asthma controller medications must have been filled during at least 2 overlapping periods of 15 days and (b) if there was a period of time between 
the concurrent dual therapy overlap (e.g., patient on monotherapy), then that period had to be 30 days or less.

Adherence to asthma long-term controller medications was measured using proportion of days covered (PDC). PDC is determined by dividing the number of days that the medication was available by the number of days in the specific interval or study period (i.e., 365 days for this study). PDC is a more conservative method of adherence estimation than MPR, another common adherence measure, for multiple medication use, drug switches, or therapeutic duplication. ${ }^{33}$ Continuous and categorical (i.e., adherent: $P D C \geq 50 \%$ and nonadherent: PDC $<50 \%)$ measures of adherence were used. Fifty percent adherence as a cutoff value was chosen based on the published literature where, on average, adherence to long-term controller medications was less than $20 \% .^{8,9}$ Because of the lower cutoff value, sensitivity analyses were not conducted.

As mentioned previously, patients with adequately controlled persistent asthma should have a minimal number of SABA claims (acceptable use is no more than 2 days per week, which would equate to 2-6 fills). Although the clinically relevant cutoff value for the number of SABA claims related to adverse events is unknown, the most frequently used and relatively conservative cutoff value is 6 claims per year. ${ }^{22-26,34-36}$ Thus, SABA claims were summed, and patients were dichotomized into 2 groups: those who had 6 or more claims in the post-index period and those who had less than 6 claims. Any claim for OCS typically indicates asthma exacerbation, and
OCS use in the post-index period was summed and operationalized as a continuous variable.

\section{Statistical Analyses}

Descriptive statistics (mean, standard deviation [SD], median, and frequency) of demographic characteristics and medication utilization patterns were employed to provide a general overview of Texas Medicaid beneficiaries with persistent asthma. A multivariate logistic regression model was used to identify the relationship between adherence (dichotomized) to controller therapies and rescue medications use while controlling for confounding variables. Multivariate linear regression was used for continuous adherence. All statistical tests were performed with SAS version 9.3 (SAS Institute, Cary, NC). Statistical tests were two-sided with an a priori significance level of $P<0.05$.

\section{Results}

During the study period, 366,012 patients had an asthma diagnosis. After employment of inclusion and exclusion criteria, the final sample size was 32,172 (see Figure 1). The majority of the total sample was aged between 5 and 11 years (63.1\%), Hispanic (54.7\%), and male (51.8\%). Overall mean \pm SD age was $15.0 \pm 14.5$. Most of the subjects were on asthma monotherapy (58.9\%). Among the 5 study asthma controller treatments, $38.6 \%$ of subjects were prescribed LTRA at index, followed by ICS/LABA fixed dose combination therapy (21.3\%) and ICS (20.3\%). Mean adherence to controller 
TABLE 1 Baseline Summary Statistics of Study Sample

\begin{tabular}{|c|c|c|}
\hline & $\mathrm{N}$ & $\%$ \\
\hline \multicolumn{3}{|l|}{ Demographic Characteristics } \\
\hline \multicolumn{3}{|l|}{ Age groups } \\
\hline $5-11$ & 20,283 & 63.1 \\
\hline $12-18$ & 6,508 & 20.2 \\
\hline Mean (SD) for children & \multicolumn{2}{|c|}{$9.1(3.4)$} \\
\hline $19-40$ & 1,763 & 5.5 \\
\hline $41-63$ & 3,618 & 11.3 \\
\hline Mean (SD) for adults & \multicolumn{2}{|c|}{$44.6(12.1)$} \\
\hline Mean (SD) overall & \multicolumn{2}{|c|}{$15.0(14.5)$} \\
\hline \multicolumn{3}{|l|}{ Race/ethnicity } \\
\hline Caucasian & 6,034 & 18.8 \\
\hline African American & 6,746 & 21.0 \\
\hline Hispanic & 17,603 & 54.7 \\
\hline Othera & 1,789 & 5.6 \\
\hline \multicolumn{3}{|l|}{ Gender } \\
\hline Female & 15,503 & 48.2 \\
\hline Male & 16,669 & 51.8 \\
\hline \multicolumn{3}{|l|}{ Clinical Characteristics } \\
\hline \multicolumn{3}{|l|}{ Therapy } \\
\hline Monotherapy & 18,948 & 58.9 \\
\hline Fixed dose dual therapy & 6,868 & 21.3 \\
\hline Concurrent dual therapyb & 6,356 & 19.8 \\
\hline \multicolumn{3}{|l|}{ Index asthma controller therapy } \\
\hline ICS & 6,522 & 20.3 \\
\hline LTRA & 12,426 & 38.6 \\
\hline ICS/LABA fixed dose dual therapy & 6,868 & 21.3 \\
\hline ICS+LTRA concurrent dual therapy & 2,828 & 8.8 \\
\hline ICS/LABA fixed dose+LTRA & 3,528 & 11.0 \\
\hline \multicolumn{3}{|l|}{ Controller therapy adherence } \\
\hline $\mathrm{PDC} \geq 80 \%$ & 1,332 & 4.1 \\
\hline $\mathrm{PDC} \geq 70 \%$ & 2,200 & 6.8 \\
\hline $\mathrm{PDC} \geq 60 \%$ & 3,338 & 10.4 \\
\hline $\mathrm{PDC} \geq 50 \%$ & 4,792 & 14.9 \\
\hline Mean (SD) & \multicolumn{2}{|c|}{$32.2(19.7)$} \\
\hline \multicolumn{3}{|l|}{ Asthma reliever utilization } \\
\hline \multicolumn{3}{|l|}{ SABA } \\
\hline None & 2,381 & 7.4 \\
\hline $1-5$ & 23,563 & 73.2 \\
\hline 6 or more & 6,228 & 19.4 \\
\hline Mean (SD) & \multicolumn{2}{|c|}{$3.7(3.1)$} \\
\hline \multicolumn{3}{|l|}{ OCS } \\
\hline None & 15,725 & 48.9 \\
\hline 1 & 8,583 & 26.7 \\
\hline 2 & 4,199 & 13.0 \\
\hline 3 & 1,952 & 6.1 \\
\hline 4 or more & 1,713 & 5.3 \\
\hline Mean (SD) & \multicolumn{2}{|c|}{$1.0(1.4)$} \\
\hline \multicolumn{3}{|c|}{ Total number of unique nonstudy medications at index date } \\
\hline 0 & 6,005 & 18.7 \\
\hline 1 & 6,836 & 21.2 \\
\hline 2 & 5,979 & 18.6 \\
\hline 3 & 4,059 & 12.6 \\
\hline 4 or more & 9,293 & 28.9 \\
\hline $\begin{array}{l}\text { Mean (SD) } \\
\end{array}$ & \multicolumn{2}{|c|}{$2.9(3.3)$} \\
\hline \multicolumn{3}{|c|}{$\begin{array}{l}{ }^{a} \text { American Indian, Asian, unknown. } \\
b \text { Concurrent dual therapy includes an inhaler and oral medication: ICS }+ \text { LTRA and } \\
\text { ICS/LABA fixed dose therapy }+L T R A \text {. Any other concurrent therapy was not includ- } \\
\text { ed, since they accounted for less than } 2 \% \text { of the concurrent dual therapy cohort. } \\
\text { ICS = inhaled corticosteroids; } L A B A=\text { long-acting beta-agonist; } L T R A=\text { leukotriene } \\
\text { receptor antagonists; OCS = oral corticosteroids; } P D C=\text { proportion of days covered; } \\
S A B A=\text { short-acting beta2-agonists; } S D=\text { standard deviation. }\end{array}$} \\
\hline
\end{tabular}

therapies was $32.2 \% \pm 19.7 \%$. When adherence was dichotomized at the cutoff points of $80 \%, 70 \%, 60 \%$, and $50 \%$, the following percentage of adherent patients were $4.1 \%, 6.8 \%$, $10.4 \%$, and $14.9 \%$, respectively (Table 1). Regarding asthma rescue medications, the majority of the sample was prescribed SABA inhalers (92.6\%), with $73.2 \%$ receiving between 1 to 5 SABA inhalers, and the overall mean number of SABA inhaler claims was $3.7 \pm 3.1$. Slightly more than one half of the sample (51.1\%) had a prescription for an OCS. About one quarter of the sample (26.7\%) received 1 prescription for OCS, and the mean number of OCS prescriptions was $1.0 \pm 1.4$. At index date, $28.9 \%$ of the sample had claims for 4 or more nonstudy medications with a mean of $2.9 \pm 3.3$.

Among LTRA monotherapy users, 19.9\% were adherent (PDC $\geq 50 \%$ ), compared with $8.9 \%$ of ICS users. Similarly, mean adherence for LTRA was higher than for ICS: $36.1 \% \pm 21.4 \%$ versus $28.0 \% \pm 16.4 \%$. Among dual therapy users, a higher percentage of patients on fixed dose dual therapy (18\%) were adherent (PDC $\geq 50 \%$ ), compared with only $6 \%$ using ICS and LTRA (concurrent dual therapy) and 9\% using ICS/LABA fixed dose inhaler in combination with LTRA.

Adherent patients were $96.7 \%$ more likely to have 6 or more prescription claims for SABA when compared with nonadherent patients (OR $=1.967,95 \% \mathrm{CI}=1.826-2.120, P<0.001$; Table 2). Similarly, as continuous adherence increased, the likelihood of having 6 or more claims for SABA increased as well $(P<0.001)$. For every 1-unit increase in adherence, subjects were 5.8 times more likely to have 6 or more prescription claims for SABA in the post-index period $(\mathrm{OR}=5.805,95 \% \mathrm{CI}=5.037-6.690)$. Additionally, patients with 6 or more SABA claims had 0.7 more OCS claims compared with patients with less than 6 claims for SABA $(P<0.001$; Table 3$)$.

Adherent patients had 0.11 fewer OCS claims compared with nonadherent patients $(P<0.001$; Table 4$)$. Compared with patients on ICS monotherapy, patients on dual therapies (ICS/ LABA fixed dose dual therapy, ICS plus LTRA concurrent dual therapy, and ICS/LABA fixed dose plus LTRA therapy) had significantly more claims for OCS, respectively $(P<0.05)$. Children (aged 5-11 years) and adults (aged 41-63 years), Hispanic patients, and those who had a higher number of nonstudy medications at index date were more likely to experience exacerbations requiring an OCS claim $(P<0.005)$.

\section{Discussion}

The present study examined the association between adherence to controller therapy among Texas Medicaid patients with persistent asthma and risk of exacerbation requiring OCS use and the use of quick-relief agents (SABA), both of which served as indicators of asthma control. Higher adherence to controller therapy was associated with a significant reduction in OCS use, whereas adherent patients were more likely to have a higher number of SABA claims. 
TABLE 2 Logistic Regression Analysis Comparing Likelihood of Having 6 or More Prescription Claims for SABA Among Adherent Versus Nonadherent Patients $(N=32,172)^{a}$

\begin{tabular}{|c|c|c|c|c|c|}
\hline & Odds Ratio & \multicolumn{2}{|c|}{$95 \%$ CI } & Wald $\mathrm{X}^{2}$ & $P$ Value ${ }^{b}$ \\
\hline \multicolumn{6}{|l|}{ Adherence to Controller Therapyc } \\
\hline Controller adherence (PDC $\geq 50 \%)$ & 1.967 & 1.826 & 2.120 & 313.9342 & $<0.0001$ \\
\hline \multicolumn{6}{|l|}{ Covariates } \\
\hline \multicolumn{6}{|l|}{ Treatment $^{c}$} \\
\hline LTRA & 0.697 & 0.641 & 0.757 & 72.0152 & $<0.0001$ \\
\hline ICS/LABA fixed dose dual therapy & 1.070 & 0.975 & 1.174 & 2.0141 & 0.1558 \\
\hline ICS+LTRA concurrent dual therapy & 1.662 & 1.492 & 1.851 & 85.0794 & $<0.0001$ \\
\hline ICS/LABA fixed dose+LTRA & 1.962 & 1.779 & 2.165 & 181.2997 & $<0.0001$ \\
\hline \multicolumn{6}{|l|}{ Age group ${ }^{c}$} \\
\hline $5-11$ & 0.832 & 0.748 & 0.925 & 11.5388 & 0.0007 \\
\hline $12-18$ & 0.881 & 0.788 & 0.985 & 4.9318 & 0.0264 \\
\hline $19-40$ & 1.114 & 0.975 & 1.273 & 2.5148 & 0.1128 \\
\hline Female & 0.844 & 0.795 & 0.896 & 30.9044 & $<0.0001$ \\
\hline \multicolumn{6}{|l|}{ Race/ethnicityc } \\
\hline African American & 1.322 & 1.214 & 1.440 & 41.1367 & $<0.0001$ \\
\hline Hispanic & 0.881 & 0.788 & 0.985 & 15.6113 & $<0.0001$ \\
\hline Otherd & 1.114 & 0.975 & 1.273 & 0.0176 & 0.8943 \\
\hline Total number of nonstudy medications & 1.052 & 1.043 & 1.061 & 132.3529 & $<0.0001$ \\
\hline \multicolumn{6}{|c|}{ 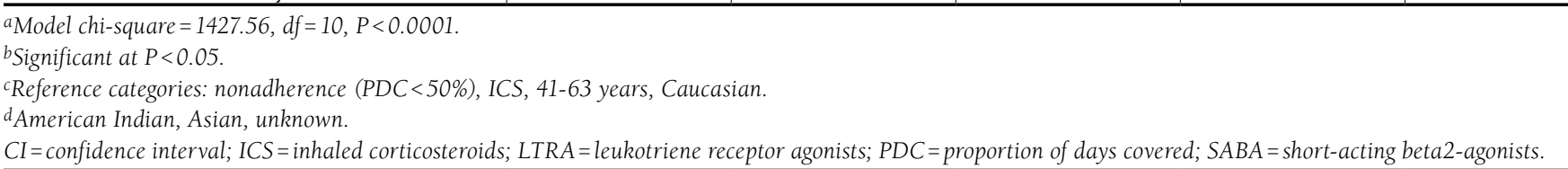 } \\
\hline
\end{tabular}

Overall, mean adherence to controller therapy in the study sample was low $(32.2 \% \pm 19.7 \%)$, which is within the reported ranges of previously conducted studies using retrospective databases. ${ }^{8,9,19,24,37}$ One of the main explanations for low adherence to controller medications may be related to characteristics of Medicaid recipients (e.g., lower socioeconomic status and predominantly Hispanics and African Americans) who have been shown to be less adherent to controller medications, compared with those enrolled in private insurance plans. ${ }^{38}$ The finding that less than $10 \%$ of patients who met the NCQA criteria for persistent asthma in the present study were adherent (PDC $\geq 50 \%)$ to ICS therapy suggests an opportunity to educate/reeducate patients with persistent asthma and their providers regarding the need for regular ICS use. In addition, health care providers should consider a more vigilant focus on at-risk populations such as younger patients (and their parents) and ethnic minorities (i.e., African-American and Hispanic patients). In this study, these patients were more likely to be nonadherent, which is congruent with earlier reported findings. ${ }^{5,39-41}$ The Hispanic population is less likely to use preventive asthma medications because of several contributing factors, including language barriers, inadequate health literacy, and cultural beliefs. ${ }^{42-45}$ Addressing these barriers in practice has shown positive results on childhood asthma among lowincome minority children. ${ }^{46,47}$ However, low levels of adherence to controller medications found in the present study in combi- nation with recent findings from another study that reported suboptimal knowledge of metered dose inhaler spacer use among caregivers of urban minority children reflects a need for education among young patients with asthma. ${ }^{48}$

Another potential explanation for low adherence to ICS can be the concept of "as needed" treatment. Although the Expert Panel Report 3 guidelines recommend daily use of ICS for all patients with persistent asthma, several clinical trials have acknowledged that ICS can be used "as needed" (when asthma symptoms worsen) for mild asthma. ${ }^{49-52}$ One of these studies (the BASALT trial) reported that "as needed" symptom-based use of ICS and traditional daily use of ICS did not differ in the time to clinical worsening of asthma. ${ }^{49}$ Nonetheless, there is not enough evidence currently to promote intermittent use of ICS for patients with mild-to-moderate asthma, even though it may occur in clinical practice. ${ }^{52} \mathrm{~A}$ higher number of nonstudy medications at the index date was associated with higher controller therapy adherence, which has been shown in other Texas Medicaid adherence studies. ${ }^{53,54}$

SABAs are used for quick relief of symptoms and are not recommended for regular use. Patients with adequately controlled persistent asthma should have a minimal number of SABA claims (acceptable use is no more than 2 days per week). Excessive SABA use indicates poor asthma control and is associated with increased asthma exacerbations and adverse

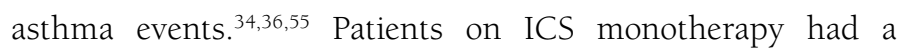




\begin{tabular}{|c|c|c|c|}
\hline \multicolumn{4}{|c|}{$\begin{array}{l}\text { Multiple Regression Analysis Comparing } \\
\text { OCS Use for Patients with } 6 \text { or More } \\
\text { Prescription Claims for SABA Versus } \\
\text { Patients with Less Than } 6 \text { Claims for } \\
\text { SABA (N=32,172) }\end{array}$} \\
\hline Factors & $\begin{array}{c}\text { Unstandardized } \\
\text { Coefficient, B }\end{array}$ & $\begin{array}{l}\text { Statistic, } \\
\text { T }\end{array}$ & $\begin{array}{c}P \\
\text { Value }^{b}\end{array}$ \\
\hline SABA claims $(\geq 6)^{\mathrm{c}}$ & 0.70391 & 34.86 & $<0.0001$ \\
\hline PDC (continuous) & -0.43870 & -10.37 & $<0.0001$ \\
\hline \multicolumn{4}{|l|}{ Treatment $^{c}$} \\
\hline LTRA & 0.01644 & 0.76 & 0.4471 \\
\hline $\begin{array}{l}\text { ICS/LABA fixed dose dual } \\
\text { therapy }\end{array}$ & 0.10372 & 4.04 & $<0.0001$ \\
\hline $\begin{array}{l}\text { ICS+LTRA concurrent dual } \\
\text { therapy }\end{array}$ & 0.02557 & 0.81 & 0.4163 \\
\hline ICS/LABA fixed dose+LTRA & 0.18076 & 6.14 & $<0.0001$ \\
\hline \multicolumn{4}{|l|}{ Age group ${ }^{c}$} \\
\hline $5-11$ & 0.17796 & 5.70 & $<0.0001$ \\
\hline $12-18$ & -0.20675 & -6.31 & $<0.0001$ \\
\hline $19-40$ & -0.06780 & -1.65 & 0.0981 \\
\hline Female & -0.01007 & -0.62 & 0.5334 \\
\hline \multicolumn{4}{|l|}{ Race/ethnicityc } \\
\hline African American & -0.07096 & -2.86 & 0.0043 \\
\hline Hispanic & 0.10973 & 5.10 & $<0.0001$ \\
\hline Otherd & -0.13495 & -3.59 & 0.0003 \\
\hline $\begin{array}{l}\text { Total number of nonstudy } \\
\text { medications }\end{array}$ & 0.04674 & 17.79 & $<0.0001$ \\
\hline \multicolumn{4}{|c|}{$\begin{array}{l}\text { a } F=167.43 \text {, adjusted } R^{2}=0.0637, P<0.0001 . \\
\text { bSignificant at } P<0.05 . \\
\text { cReference categories: } S A B A \text { claims }(<6), I C S, 41-63 \text { years, Caucasian. } \\
\text { dAmerican Indian, Asian, unknown. } \\
I C S=\text { inhaled corticosteroids; } L A B A=\text { long-acting beta2-agonists; LTRA=leukotri- } \\
\text { ene receptor agonists; OCS = oral corticosteroids; PDC= proportion of days covered; } \\
S A B A=\text { short-acting beta2-agonists. }\end{array}$} \\
\hline
\end{tabular}

significantly greater likelihood (40.8\% higher) of having 6 or more SABA claims than those on LTRA. The present study's findings were consistent with several published studies. ${ }^{22,24,56} \mathrm{~A}$ possible explanation for this finding could be related to asthma severity, since patients with more severe disease may be treated with ICS and require more SABA inhalers.

Interestingly, patients who were adherent to their monotherapy controller medications were more likely to have 6 or more claims for SABAs, when compared with nonadherent patients. Other studies have found similar results. ${ }^{5,14,23}$ The first explanation for this finding relates to the severity of asthma: it is likely that those who have less severe asthma are not highly adherent to therapy and, at the same time, have no need for excessive SABA use. However, in this study, only patients with persistent asthma were included, and total number of nonstudy medications at the index date was used as a proxy for a patient's general health status. However, factors such as allergens and other triggers, presence of comorbid conditions, or psychosocial issues may contribute to poor asthma control, even among adherent patients. ${ }^{57}$ Increasing SABA use along with increasing controller adherence may also signal to the provider that the patient may need to be evaluated for more intensive controller therapy, such as an additional agent if on monotherapy, or an increase in dose. Next, it may be that some patients filled a prescription for a SABA, but may not have used it or only used it rarely. Additionally, some patients, specifically children, may have an inhaler for home use and another inhaler for school use.

Patients on fixed dose dual therapy were $43.8 \%$ less likely to have 6 or more prescription claims for SABA than concurrent dual therapy users, which was consistent with the study by Tan et al. (2009). ${ }^{22}$ When patients on dual therapy were adherent to controller therapy, they were less likely to have 6 or more claims for SABA (by $58.8 \%$ ), compared with nonadherent patients on dual therapy. Earlier studies report conflicting results regarding the association between adherence and excessive SABA use. $^{23,31,57}$ Ambiguous results may be due to factors that are not identifiable through the prescription claims database, such as inadequate dosing or inappropriate inhalation technique. These factors can be associated with poor asthma control and, as a result, with excessive SABA use. ${ }^{57-59}$ Even though frequent use of SABA signals poor asthma control and serves as a predictor of asthma-related outcomes/subsequent exacerbations, the association between adherence to controller therapy and excessive SABA use is still unclear. $2,5,14,18,26,31,36,55,58,60$ Nevertheless, this study demonstrated that increased SABA use served as a predictor of increased OCS use, which indicates poor asthma control. Health care providers should be aware of SABA use among patients who are adherent and nonadherent to asthma controller medications. Patients with excessive SABA use should be examined for their inhaler technique and whether the dose of the controller medication is optimal. Zeiger et al. (2014) used this criterion by examining electronic medical records for excessive SABA use and intervening with an outreach program. The researchers reported a reduction in the number of subsequent SABA claims. ${ }^{61}$

OCS are used for asthma exacerbation management, which signals uncontrolled asthma. In contrast to SABA quick-relief use, this study found that better adherence to controller therapy was associated with a lower number of OCS claims, which was in line with previous research., ${ }^{3,18}$ Better adherence to controller therapy, especially among patients on dual therapy, can prevent future exacerbations and the need for OCS.

\section{Limitations}

The present study provides comprehensive analyses of adherence to various controller therapies, risk of exacerbation, and the association with rescue medication use. However, several limitations may impact the findings. First, adherence was operationalized as PDC, which may not reflect actual adherence. Just because a patient filled a prescription does not guarantee that it was used, used as prescribed, and, in the case of 


\section{Asthma Controller Medication Adherence, Risk of Exacerbation, and Use of Rescue Agents Among Texas Medicaid Patients with Persistent Asthma}

\begin{tabular}{|c|c|c|c|}
\hline $\begin{array}{l}\text { Multiple } \\
\text { OCS Use } \\
\text { Nonadh } \\
\text { (N=32,1 }\end{array}$ & \multicolumn{3}{|c|}{$\begin{array}{l}\text { Multiple Regression Analysis Comparing } \\
\text { OCS Use Among Adherent Versus } \\
\text { Nonadherent to Controller Therapy } \\
(\mathrm{N}=32,172)^{\mathrm{a}, \mathrm{b}}\end{array}$} \\
\hline & $\begin{array}{c}\text { Unstandardized } \\
\text { Coefficient, B }\end{array}$ & $\begin{array}{l}\text { Statistic, } \\
\mathrm{T}\end{array}$ & $\begin{array}{c}P \\
\text { Value }^{\mathrm{c}}\end{array}$ \\
\hline \multicolumn{4}{|l|}{ Adherence to Controller Therapyd } \\
\hline Adherence (PDC $\geq 50 \%$ ) & -0.11125 & -4.83 & $<0.0001$ \\
\hline \multicolumn{4}{|l|}{ Covariates } \\
\hline \multicolumn{4}{|l|}{ Treatment $^{\mathrm{d}}$} \\
\hline LTRA & -0.03236 & -1.48 & 0.1391 \\
\hline $\begin{array}{l}\text { ICS/LABA fixed dose dual } \\
\text { therapy }\end{array}$ & 0.10715 & 4.10 & $<0.0001$ \\
\hline $\begin{array}{l}\text { ICS + LTRA concurrent dual } \\
\text { therapy }\end{array}$ & 0.09109 & 2.85 & 0.0044 \\
\hline ICS/LABA fixed dose+LTRA & 0.26946 & 9.02 & $<0.0001$ \\
\hline \multicolumn{4}{|l|}{ Age group ${ }^{d}$} \\
\hline $5-11$ & 0.17173 & 5.42 & $<0.0001$ \\
\hline $12-18$ & -0.20480 & -6.16 & $<0.0001$ \\
\hline $19-40$ & -0.04747 & -1.14 & 0.2553 \\
\hline Female & -0.02771 & -1.68 & 0.0923 \\
\hline \multicolumn{4}{|l|}{ Race/ethnicity } \\
\hline African American & -0.03255 & -1.29 & 0.1976 \\
\hline Hispanic & 0.10294 & 4.71 & $<0.0001$ \\
\hline Othere & -0.13610 & -3.56 & 0.0004 \\
\hline $\begin{array}{l}\text { Total number of nonstudy } \\
\text { medications }\end{array}$ & 0.05288 & 19.80 & $<0.0001$ \\
\hline \multicolumn{4}{|c|}{ 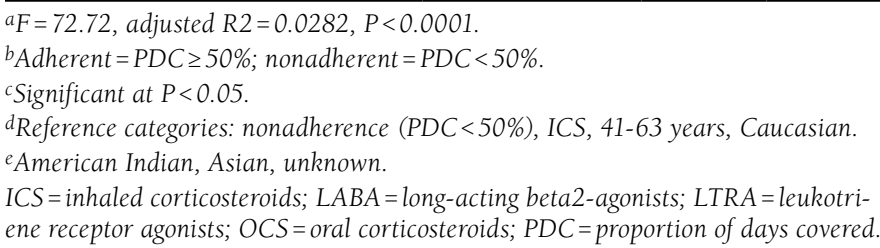 } \\
\hline
\end{tabular}

inhalers, used with the correct technique. Second, some dual therapy patients could be primarily monotherapy users who added another agent only for specific time periods. However, this study defined dual therapy as two 15-day overlapping periods, which lends validity to dual therapy use. Third, the use of a retrospective database allows only the use of the covariates that are available and gives no access to other important factors, such as clinical parameters; symptoms; and designation of mild, moderate, or severe asthma. To overcome this barrier, we used NCQA criteria for persistent asthma. Fourth, this study was cross-sectional, and causality cannot be established. Fifth, adherence to ICS can be underestimated, since a prescription reading " $1-2$ puffs $1-2$ times daily" could result in wide variations for days supply. However, pharmacists typically assume maximum use, which translates into shorter days supply. Sixth, the severity of asthma can significantly influence adherence and outcomes; however, in this study, there was no opportunity to assess this factor directly (it was not ascertainable through claims data). However, our inclusion criteria tar- geted patients with persistent asthma only. Finally, this study's findings are unique to the Texas Medicaid population, so they may not be generalizable to populations from other health care systems or to other state Medicaid programs.

\section{Conclusions}

Adherence to long-term controller medications was low among patients with asthma. Adherent patients had fewer OCS claims, indicating that adherence to controller therapy is critical in prevention of asthma exacerbations requiring OCS use. Although there was a positive relationship between adherence to long-term controller medication and SABA use, increased SABA use served as a positive predictor of increased OCS use, which indicates poor asthma control. Health care providers should be aware of OCS and SABA use among patients who are adherent and nonadherent to asthma controller medications.

\section{Authors}

TATIANA MAKHINOVA, MS, is PhD Candidate, Health Outcomes and Pharmacy Practice Division; JAMIE C. BARNER, PhD, is Professor, Health Outcomes and Pharmacy Practice Division; KAREN L. RASCATI, PhD, is Turley/Eckerd Centennial Endowed Professor, Health Outcomes and Pharmacy Practice Division; and KRISTIN M. RICHARDS, PhD, is Research Associate, Center for Pharmacoeconomic Studies, College of Pharmacy, The University of Texas at Austin.

AUTHOR CORRESPONDENCE: Jamie C. Barner, PhD, Professor, Health Outcomes and Pharmacy Practice Division, College of Pharmacy, The University of Texas at Austin, 2409 University Ave., STOP A1930, Austin, TX 78712-1120. Tel.: 512.471.5612;

Fax: 512.471.8762; E-mail: jbarner@austin.utexas.edu.

\section{DISCLOSURES}

The authors report no potential conflicts of interest.

Makhinova and Barner collaborated on the conception of the project, study design, data analysis, and writing the manuscript. Richards and Rascati critically reviewed the study design, data analysis, and results interpretation and contributed to the development and editing of the manuscript.

\section{ACKNOWLEDGMENTS}

The authors thank Texas Medicaid for the use of its data to conduct this study.

\section{REFERENCES}

1. National Center for Health Statistics. National Health Interview Survey (NHIS). 2009 data release. Centers for Disease Control and Prevention. 2010. Page updated December 14, 2012. Available at: http://www.cdc.gov/ nchs/nhis/nhis_2009_data_release.htm. Accessed October 14, 2015. 


\section{Asthma Controller Medication Adherence, Risk of Exacerbation, and Use of Rescue Agents Among Texas Medicaid Patients with Persistent Asthma}

2. National Asthma Education and Prevention Program. Expert Panel Report 3 (EPR-3): Guidelines for the diagnosis and management of asthma. Summary report 2007. NIH Publication Number 08-5846. October 2007. Available at: http://www.nhlbi.nih.gov/files/docs/guidelines/asthsumm.pdf. Accessed October 14, 2015.

3. Williams LK, Pladevall M, Xi H, et al. Relationship between adherence to inhaled corticosteroids and poor outcomes among adults with asthma. J Allergy Clin Immunol. 2004;114(6):1288-93.

4. Lasmar L, Camargos P, Champs NS, et al. Adherence rate to inhaled corticosteroids and their impact on asthma control. Allergy. 2009;64(5):784-89.

5. Williams LK, Joseph CL, Peterson EL, et al. Patients with asthma who do not fill their inhaled corticosteroids: a study of primary nonadherence. J Allergy Clin Immunol. 2007;120(5):1153-59.

6. Kandane-Rathnayake RK, Matheson MC, Simpson JA, et al. Adherence to asthma management guidelines by middle-aged adults with current asthma. Thorax. 2009;64(12):1025-31.

7. Bender BG, Pedan A, Varasteh LT. Adherence and persistence with fluticasone propionate/salmeterol combination therapy. J Allergy Clin Immunol. 2006;118(4):899-904.

8. Camargo CA, Ramachandran S, Ryskina KL, Lewis BE, Legoretta AP. Association between common asthma therapies and recurrent asthma exacerbations in children enrolled in a state Medicaid plan. Am J Health Syst Pharm. 2007;64(10):1054-61.

9. Herndon JB, Mattke S, Cuellar AE, Hong SY, Shenkman EA. Anti-inflammatory medication adherence, healthcare utilization and expenditures among medicaid and children's health insurance program enrollees with asthma. Pharmacoeconomics. 2012;30(5):397-412.

10. Gamble J, Stevenson M, McClean E, Heaney LG. The prevalence of nonadherence in difficult asthma. Am J Respir Crit Care Med. 2009;180(9):817-22.

11. Desai M, Oppenheimer JJ. Medication adherence in the asthmatic child and adolescent. Curr Allergy Asthma Rep. 2011;11(6):454-64

12. Jentzsch NS, Camargos PAM, Colosimo EA, Bousquet J. Monitoring adherence to beclomethasone in asthmatic children and adolescents through four different methods. Allergy. 2009;64(10):1458-62.

13. Bender BG, Bender SE. Patient-identified barriers to asthma treatment adherence: responses to interviews, focus groups, and questionnaires. Immunol Allergy Clin North Am. 2005;25(1):107-30.

14. Jones C, Santanello NC, Boccuzzi SJ, Wogen J, Strub P, Nelsen LM. Adherence to prescribed treatment for asthma: evidence from pharmacy benefits data. J Asthma. 2003;40(1):93-101.

15. Bozek A, Jarzab J. Adherence to asthma therapy in elderly patients. J Asthma. 2010;47(2):162-65.

16. Latry P, Pinet M, Labat A, et al. Adherence to anti-inflammatory treatment for asthma in clinical practice in France. Clin Ther. 2008;30 (Spec No):1058-68

17. McNally KA, Rohan J, Schluchter M, et al. Adherence to combined montelukast and fluticasone treatment in economically disadvantaged African American youth with asthma. J Asthma. 2009;46(9):921-27.

18. Delea TE, Stanford RH, Hagiwara M, Stempel DA. Association between adherence with fixed dose combination fluticasone propionate/salmeterol on asthma outcomes and costs. Curr Med Res Opin. 2008;24(12):3435-42.

19. Mattke S, Martorell F, Hong SY, Sharma P, Cuellar A, Lurie N. Anti-inflammatory medication adherence and cost and utilization of asthma care in a commercially insured population. J Asthma. 2010;47(3):323-29.

20. Williams LK, Peterson EL, Wells K, et al. Quantifying the proportion of severe asthma exacerbations attributable to inhaled corticosteroid nonadherence. J Allergy Clin Immunol. 2011;128(6):1185-191.e2.

21. Stern L, Berman J, Lumry W, et al. Medication compliance and disease exacerbation in patients with asthma: a retrospective study of managed care data. Ann Allergy Asthma Immunol. 2006;97(3):402-08.
22. Tan H, Sarawate C, Singer J, et al. Impact of asthma controller medications on clinical, economic, and patient-reported outcomes. Mayo Clin Proc. 2009;84(8):675-84.

23. Elkout H, Helms PJ, Simpson CR, McLay JS. Adequate levels of adherence with controller medication is associated with increased use of rescue medication in asthmatic children. PLoS One. 2012;7(6):e39130.

24. Lee TA, Chang CL, Stephenson JJ, et al. Impact of asthma controller medications on medical and economic resource utilization in adult asthma patients. Curr Med Res Opin. 2010;26(12):2851-60.

25. Wong MD, Manley RT, Stettin G, Chen W, Salmun LS. Intervention to reduce unnecessary dispensing of short-acting \{beta\}-agonists in patients with asthma. Ann Pharmacother. 2010;44(4):623-29.

26. Schatz M, Stempel D. Asthma quality-of-care measures using administrative data: relationships to subsequent exacerbations in multiple databases. Ann Allergy Asthma Immunol. 2008;101(3):235-39.

27. Global Initiative for Asthma (GINA). Global Strategy for Asthma Management and Prevention 2014. Available at: http://www.ginasthma.org/local/uploads/ files/GINA_Report_2014_Aug12_1.pdf. Accessed October 14, 2015.

28. Bender B, Zhang L. Negative affect, medication adherence, and asthma control in children. J Allergy Clin Immunol. 2008;122(3):490-95.

29. Burgess SW, Sly PD, Devadason SG. Providing feedback on adherence increases use of preventive medication by asthmatic children. J Asthma. 2010;47(2):198-201

30. Murphy AC, Proeschal A, Brightling CE, et al. The relationship between clinical outcomes and medication adherence in difficult-to-control asthma. Thorax. 2012;67(8):751-53.

31. Smith K, Warholak T, Armstrong E, Leib M, Rehfeld R, Malone D. Evaluation of risk factors and health outcomes among persons with asthma. J Asthma. 2009;46(3):234-37.

32. National Committee for Quality Assurance. National voluntary consensus standards for physician-focused ambulatory care. Appendix A-NCQA measure technical specifications. April 2008 V.7. Available at: http://www. ncqa.org/Portals/0/HEDISQM/NQF_Posting_Appendix.pdf. Accessed October 26, 2015

33. Karve S, Cleves MA, Helm M, Hudson TJ, West DS, Martin BC. Prospective validation of eight different adherence measures for use with administrative claims data among patients with schizophrenia. Value Health. 2009;12(6):989-95.

34. Stanford RH, Shah MB, D'Souza AO, Dhamane AD, Schatz M. Shortacting beta-agonist use and its ability to predict future asthma-related outcomes. Ann Allergy Asthma Immunol. 2012;109(6):403-07.

35. Schatz M, Zeiger RS, Yang ST, et al. Relationship of asthma control to asthma exacerbations using surrogate markers within a managed care database. Am J Manag Care. 2010;16(5):327-33.

36. Silver HS, Blanchette CM, Kamble S, et al. Quarterly assessment of short-acting beta(2)-adrenergic agonist use as a predictor of subsequent health care use for asthmatic patients in the United States. J Asthma. 2010;47(6):660-66.

37. Blais L, Kettani FZ, Lemière C, et al. Inhaled corticosteroids vs. leukotriene-receptor antagonists and asthma exacerbations in children. Respir Med. 2011;105(6):846-55.

38. Chang J, Freed GL, Prosser LA, et al. Comparison of health care utilization outcomes in children with asthma enrolled in private insurance plans versus Medicaid. J Pediatr Care. 2014;28(1):71-79.

39. Fredrickson DD, Molgaard CA, Dismuke SE, Schukman JS, Walling A. Understanding frequent emergency room use by Medicaid-insured children with asthma: a combined quantitative and qualitative study. J Am Board Fam Pract. 2004;17(2):96-100. 


\section{Asthma Controller Medication Adherence, Risk of Exacerbation, and Use of Rescue Agents Among Texas Medicaid Patients with Persistent Asthma}

40. Piecoro LT, Potoski M, Talbert JC, Doherty DE. Asthma prevalence, cost, and adherence with expert guidelines on the utilization of health care services and costs in a state Medicaid population. Health Serv Res. 2001;36(2):357-71

41. Lieu TA, Lozano P, Finkelstein JA, et al. Racial/ethnic variation in asthma status and management practices among children in managed Medicaid. Pediatrics. 2002;109(5):857-65.

42. Claudio L, Stingone JA. Primary household language and asthma care among Latino children. J Health Care Poor Underserved. 2009;20(3):766-79.

43. McQualid EL, Everhart RS, Seifer R, et al. Medication adherence among Latino and non-Latino white children with asthma. Pediatrics. 2012;129(6):e1404-10.

44. Kit BK, Simon AE, Ogden CL, Akinbami LJ. Trends in preventive asthma medication use among children and adolescents, 1988-2008. Pediatrics. 2012;129(1):62-69.

45. Wishnivesky JP, Kattan M, Evans D, et al. Assessing the relationship between language profficiency and asthma morbidity among inner-city asthmatics. Med Care. 2009;47(2):243-49.

46. Lob SH, Holloman Boer J, Porter PG, Núñez D, Fox P. Promoting bestcare practices in childhood asthma: quality improvement in community health centeres. Pediatrics. 2011;128(1):20-28.

47. Mosnaim G, Li H, Martin M, et al. A tailored mobile health intervention to improve adherence and asthma control in minority adolescents. J Allergy Clin Immunol Pract. 2015;3(2):288-90.el.

48. Reznik M, Silver EJ, Cao Y. Evaluation of MDI spacer utilization and technique in caregivers of urban minority children with persistent asthma. J Asthma. 2014;51(2):149-54.

49. Calhoun WJ, Ameredes BT, King TS, et al. Comparison of physician-, biomarker-, and symptom-based strategies for adjustment of inhaled corticosteroid therapy in adults with asthma: the BASALT randomized controlled trial. JAMA. 2012;308(10):987-97.

50. Boushey HA, Sorkness CA, King TS, et al. Daily versus as-needed corticosteroids for mild persistent asthma. N Engl J Med. 2005;352(15):1519-28.

51. Papi A, Canonica GW, Maestrelli P, et al. Rescue use of beclomethasone and albuterol in a single inhaler for mild asthma. N Engl J Med. 2007;356(20):2040-52
52. O'Connor GT, Reibman J. Inhaled corticosteroid dose adjustment in mild persistent asthma. JAMA. 2012;308(10):1036-37.

53. Oladapo AO, Barner JC, Rascati KL, Strassels SA. A retrospective database analysis of neuropathic pain and oral antidiabetic medication use and adherence among Texas adults with type 2 diabetes enrolled in Medicaid. Clin Ther. 2012;34(3):605-13

54. Barner JC, Khoza S, Oladapo A. ADHD medication use, adherence, persistence and cost among Texas Medicaid children. Curr Med Res Opin. 2011;27(Suppl 2):13-22.

55. Paris J, Peterson EL, Wells K, et al. Relationship between recent shortacting beta-agonist use and subsequent asthma exacerbations. Ann Allergy Asthma Immunol. 2008;101(5):482-87.

56. Ducharme FM, Nova FJ, Allen-Ramey FC, Maiese EM, Gingras J, Blais L. Clinical effectiveness of inhaled corticosteroids versus montelukast in children with asthma: prescription patterns and patient adherence as key factors. Curr Med Res Opin. 2012;28(1):111-19.

57. Broder MS, Chang EY, Kamath T, Sapra S. Poor disease control among insured users of high-dose combination therapy for asthma. Allergy Asthma Proc. 2010;31(1):60-67.

58. Butz AM, Tsoukleris M, Donithan M, et al. Patterns of inhaled antiinflammatory medication use in young underserved children with asthma. Pediatrics. 2006;118(6):2504-13.

59. Walders N, Kopel SJ, Koinis-Mitchell D, McQuaid EL, et al. Patterns of quick-relief and long-term controller medication use in pediatric asthma. J Pediatr. 2005;146(2):177-82

60. Allen-Ramey FC, Bukstein D, Luskin A, Sajjan SG, Markson LE. Administrative claims analysis of asthma-related health care utilization for patients who received inhaled corticosteroids with either montelukast or salmeterol as combination therapy. J Manag Care Pharm. 2006;12(4):310-21. Available at: http://amcp.org/data/jmcp/310-321.pdf.

61. Zeiger R, Schatz M, Li Q, et al. Real-time asthma outreach reduces excessive short-acting $\beta 2$-agonist use: a randomized study. J Allergy Clin Immunol Pract. 2014;2(4):445-56. 